\title{
Blood pressure:
}

\section{at what level is treatment worthwhile?}

\section{SUMMARY}

High blood pressure is a key modifiable risk factor for cardiovascular events. A cardiovascular riskbased approach is best for determining when to start antihypertensive treatment.

Recent trial evidence has suggested lower blood pressure targets are beneficial. This has influenced international guidelines. The US guidelines have a lower threshold for defining hypertension than current Australian and European guidelines.

The patient's individual circumstances must be considered when treatment targets are set. For someone with a high risk of cardiovascular events, a systolic blood pressure target of $120 \mathrm{mmHg}$ may be appropriate.

\section{Introduction}

High blood pressure is one of the key modifiable risk factors for adverse cardiovascular outcomes such as heart attack and stroke. Lifestyle changes including a healthy diet, quitting smoking, and increasing exercise are effective at reducing blood pressure. However many people will require antihypertensive drugs to reduce their blood pressure.

There has been much debate about the interpretation of observational data describing the relationship between blood pressure and cardiovascular outcomes. Studies of low-risk individuals reported log-linear relationships between systolic blood pressure and cardiovascular events down to the lowest levels for which adequate data were available (about $115 \mathrm{mmHg}$ ). Meanwhile other studies included people at a higher risk of cardiovascular events, where many or even all had existing cardiovascular disease. These studies found that the lowest risk was at about 130-140 mm systolic, but suggested that blood pressure below this range was associated with a higher cardiovascular risk. This is the so-called J-curve. ${ }^{2}$

The challenge in interpreting these data is that they are likely to be confounded by reverse causality. This is when cardiovascular disease causes both lower blood pressure and a high risk of cardiovascular events and death, but the blood pressure level itself is not necessarily responsible for the higher risk of death.

\section{Treatment targets in hypertension}

Several large trials have randomised participants to different targets for systolic blood pressure. The most recent is the Systolic Blood Pressure Intervention Trial (SPRINT), where 9361 people at high cardiovascular risk, but without diabetes, were randomised to systolic targets of $<120 \mathrm{mmHg}$ (intensive treatment) or $<140 \mathrm{mmHg}$ (standard treatment). ${ }^{3}$ The trial was stopped early (mean follow-up 3.3 years) due to a clear reduction of cardiovascular events in the intensive treatment arm (hazard ratio (HR) 0.75, 95\% confidence interval (Cl) 0.64-0.89) as well as reduced all-cause mortality (HR 0.73, 95\% Cl 0.60-0.90).

Previous trials had suggested similar effects but may have been underpowered. In the Action to Control Cardiovascular Risk in Diabetes (ACCORD) trial all 10,251 participants were randomised to more or less intensive control of blood glucose and then 4733 participants went into the blood pressure trial (blood pressure targets $<120 \mathrm{mmHg}$ vs $<140 \mathrm{mmHg})^{4,5}$ However, a lower than anticipated event rate and shorter follow-up left the trial underpowered and there was no statistically significant difference between arms in event rates (HR 0.88, 95\% Cl 0.73-1.06).

The glucose arm may have confounded the results as intensive glucose control increased the risk of cardiovascular and total mortality. ${ }^{6}$ Long-term followup revealed statistically significant benefits for lower blood pressure targets in the patients randomised to standard glucose control (HR 0.75, 95\% Cl 0.60-0.95)? The third Stroke Prevention Study (SPS3) compared systolic blood pressure targets (130-149 $\mathrm{mmHg}$ vs $<130 \mathrm{mmHg}$ ) in 3020 people with a history of recent lacunar stroke. There was no statistically significant effect on stroke (HR 0.81, 95\% Cl 0.64-1.03), or the composite end point of myocardial infarction, stroke and cardiovascular death (HR 0.84, 95\% Cl 0.68-1.04), but intracerebral haemorrhage was significantly reduced (HR 0.37, 95\% $\mathrm{Cl} 0.15-0.95$ ) with intensive blood pressure lowering. ${ }^{8}$ Again, this trial experienced lower event rates than anticipated in the statistical

\section{Emily R Atkins \\ Research fellow' \\ Vlado Perkovic \\ Professor \\ 'The George Institute for Global Health, UNSW \\ Sydney}

\section{Keywords}

antihypertensive drugs, blood pressure, cardiovascular risk, hypertension

Aust Prescr 2019:42:127-30 https://doi.org/10.18773/ austprescr.2019.038

Corrected 1 October 2019

Correction notice

available at:

https://doi.org/10.18773/

austprescr.2019.062

Corrected 19 December 2019

Correction notice

available at:

https://doi.org/10.18773/

austprescr.2019.078

This is the corrected version of the article. 
power calculations, possibly meaning that it might have missed a real benefit.

A systematic review assessed all the evidence of more versus less intensive blood pressure lowering. ${ }^{9}$ The meta-analysis of 20 trials found significant benefits for more intensive treatment on major cardiovascular events (relative risk $0.85,95 \% \mathrm{Cl} 0.78-0.94)^{10}$ which were generalisable across a variety of patient populations." There was a small but statistically significant difference in severe hypotension with intensive treatment $(0.3 \%$ vs $0.1 \%$ per person-year follow-up), but no statistically significant difference in severe adverse events associated with blood pressure lowering, dizziness or adverse events leading to discontinuation of treatment. ${ }^{9}$

Taken together, the evidence suggests that aiming for a target blood pressure of $120 / 80 \mathrm{mmHg}$ will lead to a lower risk of cardiovascular events compared to a target of 140/90 mmHg among high-risk individuals. There is a small increase in the risk of adverse events with a lower target. These data can be used to inform patients so that they can make relevant decisions about the intensity of blood pressure lowering they would prefer.

\section{What the guidelines say}

There are Australian and international guidelines for the treatment of hypertension (see Table).12-14 The Australian National Heart Foundation guidelines were already out for public consultation when the SPRINT results were published. Incorporation of these results into the guidelines happened late, ${ }^{12}$ and with cautious interpretation of the results.
International guidelines including those in the USA (ACC/AHA guidelines) ${ }^{13}$ and Canada ${ }^{15}$ were revised with lower thresholds for starting treatment and lower treatment targets. The guidelines of the American College of Physicians and the American Academy for Family Physicians are an exception. They recommend starting treatment at $150 \mathrm{mmHg}$ and with targets below 150/90 mmHg for people aged 60 years and older. ${ }^{16}$

The ACC/AHA guidelines ${ }^{13}$ have a lower threshold for defining hypertension than the current Australian ${ }^{12}$ and European ${ }^{14}$ guidelines. The Australian and European guidelines are similar on when to start therapy, but Australia has lower treatment targets.

\section{Controversies concerning recent recommendations}

A source of contention in interpreting the SPRINT results is understanding how unattended automated measurement of blood pressure relates to usual practice. SPRINT used an average of three measures, one minute apart, after five minutes of unattended rest but the protocol did not specify that the study staff remain out of the room after the rest period, ${ }^{17}$ so it may not have been entirely unattended. The Australian guidelines also recommend three measurements are taken after 'several minutes' rest with an average of the last two measures taken. For cardiovascular risk equations, measurements taken in the clinic should be used as this is what was used to derive the equations. ${ }^{12}$ The Australian guidelines suggest using a mercury sphygmomanometer or automated digital device, noting mercury is being phased out of clinical use. ${ }^{12}$ Use of an automated device has a demonstrated

\section{Table Comparison of international guidelines for the treatment of hypertension}

\begin{tabular}{|c|c|c|c|c|c|c|}
\hline \multirow{3}{*}{ Hypertension definition $(\mathrm{mmHg})$} & \multicolumn{2}{|c|}{ Australia $2016^{12}$} & \multicolumn{2}{|c|}{ USA $2017^{13}$} & \multicolumn{2}{|c|}{ Europe $2018^{14}$} \\
\hline & \multicolumn{2}{|c|}{$\geq 140 / 90$} & \multicolumn{2}{|c|}{$\geq 130 / 80$} & \multicolumn{2}{|c|}{$\geq 140 / 90$} \\
\hline & $\begin{array}{l}\text { Start } \\
\text { treatment }\end{array}$ & $\begin{array}{l}\text { Treatment } \\
\text { target }\end{array}$ & $\begin{array}{l}\text { Start } \\
\text { treatment }\end{array}$ & $\begin{array}{l}\text { Treatment } \\
\text { target }\end{array}$ & $\begin{array}{l}\text { Start } \\
\text { treatment }\end{array}$ & $\begin{array}{l}\text { Treatment } \\
\text { target }\end{array}$ \\
\hline General population & $\geq 160 / 100^{*}$ & $<140 / 90$ & $\geq 140 / 90$ & $<130 / 80$ & $\geq 160 / 90^{*}$ & $<130 / 80$ \\
\hline High cardiovascular risk & $\geq 140 / 90$ & $<120 /-$ & $\geq 130 / 80$ & $<130 / 80$ & $\geq 140 / 90^{\dagger}$ & $<130 / 80$ \\
\hline Older age $\ddagger$ & - & $<120 /-$ & $\geq 130 /-$ & $<130 /-$ & $\begin{array}{l}\geq 140 / 90 \\
\text { Age } 80+160 / 90\end{array}$ & $<130 / 80$ \\
\hline Diabetes & $\geq 140 / 90$ & $<120 / 90$ & $\geq 130 / 80$ & $<130 / 80$ & $\geq 140 / 90$ & $<130 / 80$ \\
\hline Kidney disease & $\geq 140 / 90$ & $<120 / 90$ & $\geq 130 / 80$ & $<130 / 80$ & $\geq 140 / 90$ & $<140 / 80$ \\
\hline
\end{tabular}

* For those with a systolic blood pressure of 140-159 mmHg treatment may begin after a period of lifestyle advice.

+ Treatment may be considered in those with coronary disease or stroke with a systolic blood pressure of 130-140 mmHg.

$\ddagger$ Older people are $\geq 75$ years in Australian guidelines, $\geq 65$ years in US guidelines, while the European guidelines include separate recommendations for $65-79$ years and $\geq 80$ years. 
reduction in digit preference, and improved accuracy of recordings in Australian primary care. ${ }^{18} \mathrm{~A}$ recent study has shown auscultatory, attended automated, and unattended automated blood pressure measurements conducted by general practitioners are comparable. The impact of this different measurement protocol may therefore be clinically minor. ${ }^{19}$

There are concerns about the potential harm from more people starting treatment at lower blood pressures. ${ }^{20}$ The common adverse effects of antihypertensive therapy can be grouped two ways:

- effects of the particular drug chosen (e.g. cough associated with ACE inhibitors)

- effects of blood pressure lowering (often hypotension and syncope).

Concerns have been raised about renal safety due to the statistically significant difference in participants without chronic kidney disease experiencing at least a $30 \%$ reduction in estimated glomerular filtration rate (eGFR) in SPRINT. ${ }^{3}$ However this measure is not a clinically meaningful outcome in people with eGFR above $60 \mathrm{~mL} / \mathrm{min} / 1.73 \mathrm{~m}^{2}$. For those with chronic kidney disease, there was no significant difference in the composite renal outcomes, but there was insufficient power to determine if there was any effect on long-term dialysis.

The systematic review revealed no significant differences in severe adverse events associated with blood pressure lowering, dizziness or adverse events leading to discontinuation of more intensive blood pressure lowering therapy. However, there was a small difference in severe hypotension. ${ }^{9}$

\section{Are Australians being undertreated or are Americans being over treated?}

Australians could probably benefit from earlier treatment if they have a high cardiovascular risk. Australian guidelines start treatment at a higher threshold and involve a slower process of treatment escalation, but have lower treatment targets than the USA. The evidence suggests starting treatment at a lower level and aiming for a lower target will prevent more heart attacks, strokes and premature deaths from cardiovascular causes. Treatment individualisation based on absolute risk, tolerance, safety and efficacy should guide treatment decisions. Take into account patient characteristics, including how they value the potential harms and benefits.

\section{At what level is treatment worthwhile?}

A cardiovascular risk-based approach is best for determining when to begin treatment for lowering blood pressure (see the Australian absolute cardiovascular disease risk calculator). Many cardiovascular events happen in people with blood pressure below $140 \mathrm{mmHg}$ and at high cardiovascular risk, or with existing cardiovascular disease..$^{21}$ The benefits for treating individuals at high cardiovascular risk may be substantial, down to a systolic blood pressure of $120 \mathrm{mmHg}$. For example, if someone has a systolic blood pressure of $130-140 \mathrm{mmHg}$ and is at high risk of a cardiovascular event ( $>15 \%$ over five years) then treatment is likely to be worthwhile. Important considerations include other conditions that further add to cardiovascular risk. These may not be adequately accounted for in existing risk equations. Examples include atrial fibrillation, obesity, socioeconomic deprivation, chronic kidney disease, and a history of high blood pressure during pregnancy. Consider the person's treatment preferences, occupation, lifestyle and risk aversion when determining when to start treatment. Patients should choose the blood pressure target that gives them the best combination of cardiovascular benefit and tolerability. This is likely to vary substantially between individuals. Discuss the importance of adherence to the chosen treatment and the options available to aid adherence.

\section{Conclusion}

Treatment for lowering blood pressure is worthwhile in those at high risk of a cardiovascular event ( $>15 \%$ in 5 years). Aiming for a target systolic blood pressure below $120 \mathrm{mmHg}$ can ensure maximal cardiovascular risk reduction if the treatment is tolerated and is appropriate for the individual patient. «

Emily Atkins was supported by a postdoctoral fellowship (PdF 101884) from the National Heart Foundation of Australia.

Vlado Perkovic has served on steering committees, advisory boards, or given scientific presentations supported by Abbvie, Astellas, Astra Zeneca, Bayer, Baxter, MBS, Boehringer Ingelheim, Dimerix, Durect, Eli Lilly, Gilead, GSK, Janssen, Merck, Metavant, Mitsubishi Tanabe, Mundipharma, Novartis, Novo Nordisk, Pfizer, Pharmalink, Relypsa, Retrophin, Sanofi, Servier, Vifor and Tricida.

\section{REFERENCES}

1. MacMahon S, Peto R, Cutler J, Collins R, Sorlie P, Neaton J, et al. Blood pressure, stroke, and coronary heart disease. Part 1, Prolonged differences in blood pressure: prospective observational studies corrected for the regression dilution bias. Lancet 1990;335:765-74. https://doi.org/10.1016/ 0140-6736(90)90878-9
2. Farnett L, Mulrow CD, Linn WD, Lucey CR, Tuley MR. The $J$-curve phenomenon and the treatment of hypertension. s there a point beyond which pressure reduction is dangerous? JAMA 1991;265:489-95. https://doi.org/10.1001/ jama.1991.03460040065031 
3. SPRINT Research Group. A randomized trial of intensive versus standard blood-pressure control. N Engl J Med 2015;373:2103-16. https://doi.org/10.1056/NEJMoa1511939

4. ACCORD Study Group. Effects of intensive bloodpressure control in type 2 diabetes mellitus. N Engl J Med 2010;362:1575-85. https://doi.org/10.1056/NEJMoa1001286

5. Buse JB, Bigger JT, Byington RP, Cooper LS Cushman WC, Friedewald WT, et al.; ACCORD Study Group. Action to Control Cardiovascular Risk in Diabetes (ACCORD) trial: design and methods. Am J Cardiol 2007;99(Supplement):S21-S33. https://doi.org/10.1016/ j.amjcard.2007.03.003

6. Margolis KL, O'Connor PJ, Morgan TM, Buse JB, Cohen RM, Cushman WC, et al. Outcomes of combined cardiovascular risk factor management strategies in type 2 diabetes: the ACCORD randomized trial. Diabetes Care 2014;37:1721-8. https://doi.org/10.2337/dc13-2334

7. Buckley LF, Dixon DL, Wohlford GF 4th, Wijesinghe DS, Baker WL, Van Tassell BW. Effect of intensive blood pressure control in patients with type 2 diabetes mellitus over 9 years of follow-up: a subgroup analysis of high-risk ACCORDION trial participants. Diabetes Obes Metab 2018;20:1499-502. https://doi.org/10.1111/dom.13248

8. SPS3 Study Group. Blood-pressure targets in patients with recent lacunar stroke: the SPS3 randomised trial. Lancet 2013;382:507-15. https://doi.org/10.1016/ S0140-6736(13)60852-1

9. Xie X, Atkins E, Lv J, Bennett A, Neal B, Ninomiya T, et al. Effects of intensive blood pressure lowering on cardiovascular and renal outcomes: updated systematic review and meta-analysis. Lancet 2016;387:435-43. https://doi.org/10.1016/S0140-6736(15)00805-3

10. Atkins ER, Rodgers A. More versus less blood pressure lowering: an update. Clin Ther 2016;38:2135-41. https://doi.org/10.1016/j.clinthera.2016.08.007

11. Xie X, Atkins E, Lv J, Rodgers A. Intensive blood pressure lowering - Authors' reply. Lancet 2016;387:2291. https://doi.org/10.1016/S0140-6736(16)30366-X

12. National Heart Foundation of Australia. Guideline for the diagnosis and management of hypertension in adults - 2016 . Melbourne: NHFA; 2016. https://www.heartfoundation.org.au/ for-professionals/clinical-information/hypertension [cited 2019 Jul 1]

13. Whelton PK, Carey RM, Aronow WS, Casey DE Jr, Collins KJ, Dennison Himmelfarb C, et al. ACC/AHA/AAPA/ABC/ ACPM/AGS/APhA/ASH/ASPC/NMA/PCNA Guideline for the prevention, detection, evaluation, and management of high blood pressure in adults: executive summary: A report of the American College of Cardiology/American Heart Association Task Force on clinical practice guidelines. Hypertension 2018;71:1269-324. https://doi.org/10.1161/ HYP.0000000000000066
14. Williams B, Mancia G, Spiering W, Agabiti Rosei E, Azizi M, Burnier M, et al.; ESC Scientific Document Group. 2018 ESC/ ESH Guidelines for the management of arterial hypertension. Eur Heart J 2018;39:3021-104. https://doi.org/10.1093/ eurheartj/ehy339

15. Leung AA, Nerenberg K, Daskalopoulou SS, McBrien K, Zarnke KB, Dasgupta K, et al.; CHEP Guidelines Task Force. Hypertension Canada's 2016 Canadian hypertension education program guidelines for blood pressure measurement, diagnosis, assessment of risk, prevention, and treatment of hypertension. Can J Cardiol 2016;32:569-88. https://doi.org/10.1016/j.cjca.2016.02.066

16. Qaseem A, Wilt TJ, Rich R, Humphrey LL, Frost J, Forciea MA; Clinical Guidelines Committee of the American College of Physicians and the Commission on Health of the Public and Science of the American Academy of Family Physicians. Pharmacologic treatment of hypertension in adults aged 60 years or older to higher versus lower blood pressure targets: a clinical practice guideline from the American College of Physicians and the American Academy of Family Physicians. Ann Intern Med 2017;166:430-7. https://doi.org/10.7326/M16-1785

17. Systolic Blood Pressure Intervention Trial (SPRINT). MOP versions related to SPRINT blood pressure measurement technique [PDF]. Updated 2014 Dec 19. https://www.sprinttrial.org/public/MOP_Excerpt_about_ BP_Measurement.pdf [cited 2019 Jul 1].

18. Nelson MR, Quinn S, Bowers-Ingram L, Nelson JM, Winzenberg TM. Cluster-randomized controlled trial of oscillometric vs. manual sphygmomanometer for blood pressure management in primary care (CRAB). Am J Hypertens 2009;22:598-603. https://doi.org/10.1038/ ajh.2009.55

19. Bauer F, Seibert FS, Rohn B, Bauer KA, Rolshoven E, Babel N, et al. Attended versus unattended blood pressure measurement in a real life setting. Hypertension 2018;71:243-9. https://doi.org/10.1161/HYPERTENSIONAHA.117.10026

20. Bell KJ, Doust J, Glasziou P. Incremental benefits and harms of the 2017 American College of Cardiology/ American Heart Association high blood pressure guideline. JAMA Intern Med 2018;178:755-7. https://doi.org/10.1001/ jamainternmed.2018.0310

21. Karmali KN, Ning H, Goff DC Jr, Lloyd-Jones DM. Identifying individuals at risk for cardiovascular events across the spectrum of blood pressure levels. J Am Heart Assoc 2015;4:e002126. https://doi.org/10.1161/JAHA.115.002126 